\title{
Population Dynamics of Sylhet City Corporation: A Mathematical Approach
}

Kazi Md. Jahid Hasan

Lecturer, Leading University, Sylhet, Bangladesh

\begin{abstract}
For the sustainable development of a country or a city, it is important to know the accurate idea of the population of that region. The local authorities can easily implement their various development plans if they know the future scenario of the population. This study aims to forecast the population of Sylhet City Corporation, which was transformed into a city corporation 20 years ago. Three frequently used and popular methods of population forecasting Arithmetic Increase Method, Geometric Increase Method, and Incremental Increment Method are used to forecast the population. Population data from 2001 to 2015 are used to train and data from 2016 to 2021 are used to verify the methods. The average percentage of error of these three methods is about 3\%. Among the three methods, the Geometric Increase Method provides the best result with a percentage of error of $0.15655 \%$.
\end{abstract}

Keywords: Population prediction, Sylhet City Corporation, Geometric Increase Method.

\section{Introduction}

Bangladesh is a populous country with a high density of population. Sylhet, the north-eastern part of Bangladesh, is a rapidly growing city. Since Sylhet was upgraded from a municipality to a city corporation in 2001, people have moved to the city to get better civic benefits. Knowing the type of population growth in Sylhet or what the population might be in the future will help policymakers to make decisions. Sylhet is the most earthquake-prone area of Bangladesh. Ara (2014) analyzed the impact of the sequential distribution of the population living in an earthquake-prone area to realize a pragmatic assessment. Population forecasting plays an important role to local authorities, businessmen and researchers for many purposes (Chi et al. 2011). Kabir and Chowdhury (1982) inspected the connection between growth rate and food production in Bangladesh. Recognizing the difficulty of feeding the growing population even with a substantial increase in food production, they suggested giving priority to population policy for a discount in population. Hoque et al.(1995) estimated the future population of Bangladesh. Mallick (1980) investigated the population trend in Bangladesh and predicted that the growth rate will be zero in the next hundred years was very impractical. Exponential growth models and models utilizing a Markov chain were developed by Beekman (1984) to reflect lower birth rates caused by rural-urban movement.

Rahman (1993) used the formula

$$
P_{t}=P_{0} e^{(r+k) t}
$$

where $P_{0=}$ current population; $P_{t}=$ population after time $\mathrm{t} ; \mathrm{r}=$ growth rate and $\mathrm{k}$ is annual migration rate, for prediction of regional population.

An assessment of 30 years of local government area population forecasts in Australia found the median absolute percentage error to be $5.4 \%$ after ten years for local areas as an entire but much greater for the littlest populations, like $13.3 \%$ for areas with under 1,000 people at the beginning of the forecasts (Wilson et al. 2018). Wilson et al.(2018), Rayer (2008), Rayer and Smith (2014), Statistics New Zealand (2008), Tayman (2011), Yamauchi et al.(2017) found that forecast error tends to 
extend as population size decreases and usually increases the further into the longer term the forecasts extend, findings common to several forecast evaluation studies.

\section{Study Area:}

Sylhet City Corporation is located in between $24^{\circ} 51^{\prime}$ and $24^{\circ} 55^{\prime}$ north latitudes and in between $91^{\circ} 50^{\prime}$ and 91 ${ }^{\circ} 4^{\prime}$ east longitudes. The area of the Sylhet City Corporation is $27.36 \mathrm{sq} \mathrm{km}$. It is located in the northeastern part of Bangladesh and is bounded by Sylhet Sadar upazila on the north, Dakshin Surma upazila on the south, Sylhet Sadar upazila on the east and Dakshin Surma upazila on the west.

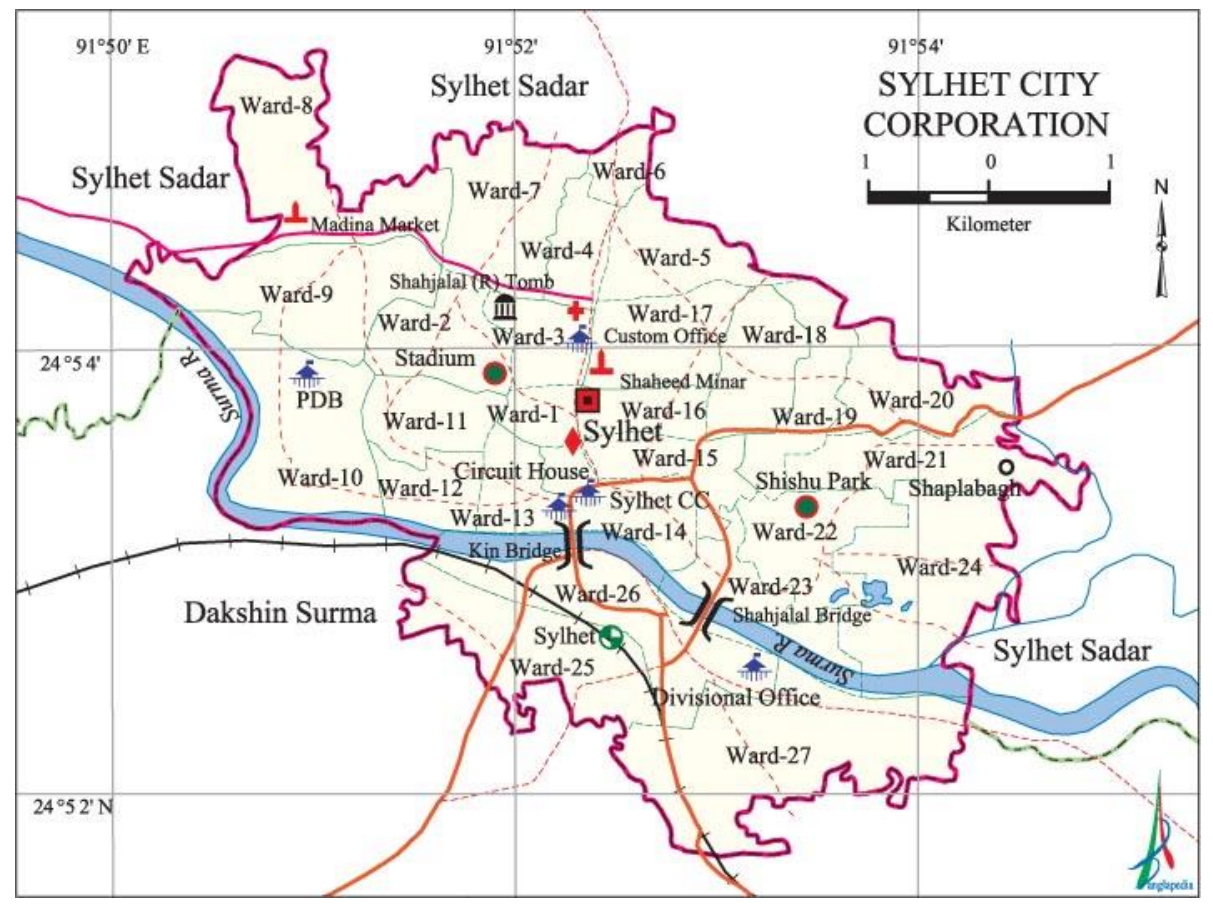

\section{Data Collection:}

For this study, secondary data of the population of Sylhet City Corporation is used. Yearly data of population is collected from the Sylhet City Corporation for the study period of 2001 to 2021. Populations from 2001 to 2015 were used to develop the forecasting model by three different methods while data from 2016 to 2021 were used to verify the prediction precision.

\section{Methods:}

To predict the population of a city, the following methods are commonly used (nptel.ac.in, 2018):

1) Arithmetic Increase method

2) Geometric Increase method

3) Incremental Increment method

\section{Arithmetic Increase method:}

In the arithmetic increase method, it is assumed that the population increases from year to year at a constant rate. This average increase in population is calculated from the past year's data. The population of the upcoming years is obtained by adding the mean increase population to the present population.

Population after n-th years will be $P_{n}=P+n . C$

Where $\mathrm{P}=$ Present population

$$
\mathrm{C}=\text { Constant }=\mathrm{dP} / \mathrm{dt}
$$

This method gives better results for large and developed cities. For small and comparatively new cities, it will give a lower estimate than the actual value. 


\section{Geometric Increase method:}

The geometric increase method is used by letting the percentage growth rate of the population is constant. The population of the next years is calculated by the following equation

$$
P_{n}=P(1+g)^{n}
$$

Where $g=$ Geometric mean of the rate of growth of the previous year

$$
\mathrm{n}=\text { Number of years }
$$

This method is more applicable to new cities than the rapidly grown cities within a shorter time.

\section{Incremental Increase method:}

By modifying the arithmetic increase method, this method is obtained. This method is suitable for cities of an average size where the growth rate is in increasing order. Population after $n$-th years is estimated by the following equation:

$$
P_{n}=P+n \cdot x+\left(\frac{n(n+1)}{2}\right) y
$$

Where, $x=$ Average increase of the past years

$\mathrm{y}=$ Incremental increase

\section{Result and Discussion:}

Table-1: Population of Sylhet City Corporation (2001-2021)

\begin{tabular}{|c|c|c|c|}
\hline Year & Population & Year & Population \\
\hline 2001 & 343,000 & 2012 & 582,000 \\
\hline 2002 & 360,000 & 2013 & 610,000 \\
\hline 2003 & 378,000 & 2014 & 640,000 \\
\hline 2004 & 396,000 & 2015 & 672,000 \\
\hline 2005 & 416,000 & 2016 & 705,000 \\
\hline 2006 & 436,000 & 2017 & 740,000 \\
\hline 2007 & 458,000 & 2018 & 776,000 \\
\hline 2008 & 480,000 & 2019 & 814,000 \\
\hline 2009 & 504,000 & 2020 & 852,000 \\
\hline 2010 & 529,000 & 2021 & 890,000 \\
\hline 2011 & 555,000 & & \\
\hline
\end{tabular}

Arithmetic Increase method:

Table-2: Predicted population of Sylhet City Corporation using Arithmetic Increase Method for 20152021

\begin{tabular}{|c|c|c|c|}
\hline Year & Actual Population & Predicted Population & $\begin{array}{c}\text { Percentage of } \\
\text { Error }\end{array}$ \\
\hline 2016 & 705,000 & 695,500 & 1.35 \\
\hline 2017 & 740,000 & 719,000 & 2.84 \\
\hline 2018 & 776,000 & 742,500 & 4.32 \\
\hline 2019 & 814,000 & 766,000 & 5.90 \\
\hline 2020 & 852,000 & 789,500 & 7.34 \\
\hline 2021 & 890,000 & 813,000 & 8.65 \\
\hline \multicolumn{2}{|r|}{ Average Percentage of Error } \\
\hline
\end{tabular}

Average increment of population from 2001 to 2015 was 23,500. This method provided under estimation and forecasted the population with average error $5.07 \%$. 


\section{Geometric Increase method:}

Table-3: Predicted population of Sylhet City Corporation using Geometric Increase Method for 20162021

\begin{tabular}{|c|c|c|c|}
\hline Year & Actual Population & Predicted Population & Percentage of Error \\
\hline 2016 & 705,000 & 704,861 & 0.0197 \\
\hline 2017 & 740,000 & 739,328 & 0.0908 \\
\hline 2018 & 776,000 & 775,482 & 0.0668 \\
\hline 2019 & 814,000 & 813,403 & 0.0733 \\
\hline 2020 & 852,000 & 853,178 & -0.1383 \\
\hline 2021 & 890,000 & 894,899 & -0.5504 \\
\hline \multicolumn{3}{|c|}{ Average Percentage of Error } \\
\hline
\end{tabular}

Geometric mean $(\mathrm{g})$ of the geometrical increase rate of growth is founded 0.0489. Geometric increase method forecasted with average error $0.15655 \%$. In 2020 and 2021, this method provided over estimation. Incremental Increase method:

Table-4: Predicted population of Sylhet City Corporation using Incremental Increase Method for 20162021

\begin{tabular}{|c|c|c|c|}
\hline Year & Actual Population & Predicted Population & Percentage of Error \\
\hline 2016 & 705,000 & 696,654 & 1.18 \\
\hline 2017 & 740,000 & 722,462 & 2.37 \\
\hline 2018 & 776,000 & 749,424 & 3.42 \\
\hline 2019 & 814,000 & 777,540 & 4.48 \\
\hline 2020 & 852,000 & 806,810 & 5.30 \\
\hline 2021 & 890,000 & 837,234 & 5.93 \\
\hline \multicolumn{3}{|c|}{ Average Percentage of Error } \\
\hline
\end{tabular}

Incremental Increase Method forecasted with average error $3.78 \%$ and provided under estimation.

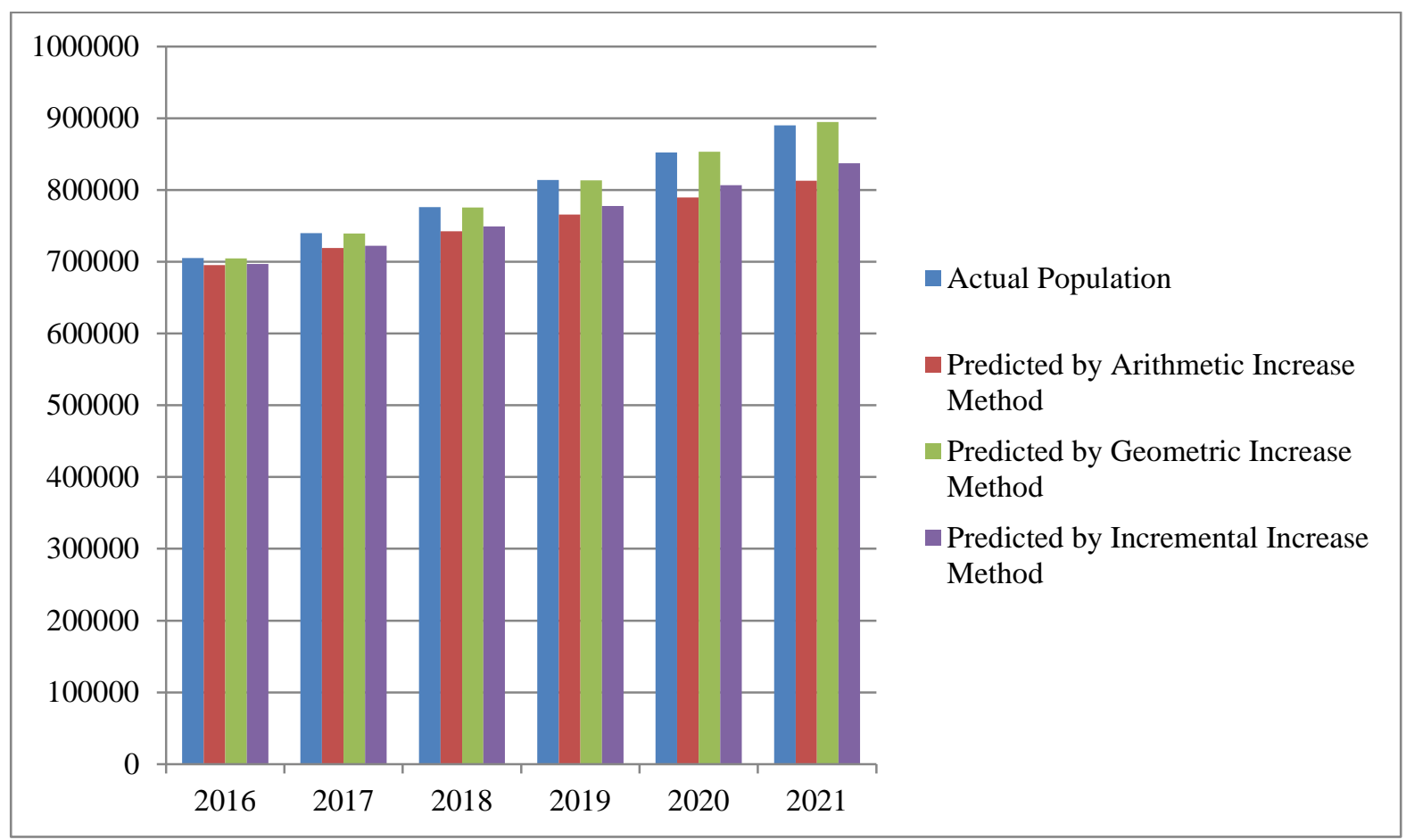

Figure-1: Comparison between the actual and predicted population 
From Table-2, Table-3, Table-4 and Figure-1, it is evident that the population predicted by the Geometric Increase Method was more accurate than the other methods. Arithmetic Increase Method provided the highest average percentage of error (5.07\%).

Table-5: Predicted Population of Sylhet City Corporation for 2022-2030

\begin{tabular}{|c|c|}
\hline Year & Predicted Population \\
\hline 2022 & 938,659 \\
\hline 2023 & 984,559 \\
\hline 2024 & $1,032,704$ \\
\hline 2025 & $1,083,204$ \\
\hline 2026 & $1,136,172$ \\
\hline 2027 & $1,191,731$ \\
\hline 2028 & $1,250,007$ \\
\hline 2029 & $1,311,132$ \\
\hline 2030 & $1,375,247$ \\
\hline
\end{tabular}

\section{Conclusion:}

Three popular population forecasting methods were used to predict the population of Sylhet City Corporation. The geometric increase method provides a significant result with less percentage of error among the three methods. The geometric increase method can be applied to forecast the population of a rapidly growing city like Sylhet. In this study, the population has been predicted till 2030. This study will help to understand the population growth rate of the city. By knowing the probable population of the city, authorities will be able to execute their different development plans. If the area of the city is increased in the future, the pattern of the growth rate of the population will be changed. This study was limited to one parameter like growth rate. Different types of research can be done by including other parameters like immigration rate and the rate of the people leaving the city.

\section{References:}

1. Kabir, M. and Chowdhury, A. A.(1982). Population Growth and Food Production in Bangladesh, Rural Demography, IX (1 \& 2): 25-56

2. Mallick, A. A. (1980), Implausibility of Attaining Zero Population Growth in Banthin Next 100 Years, Rural Demography, VII (1 \& 2): 33-39

3. Beekman, J. A.(1984), Population and Social Security Projection Techniques, Rural Demography”, XI (1 \& 2): 1-20.

4. Rahman, M. M. (1993), National Growth Rate Method with Varying Internal Migration Rate, The Bangladesh Development Studies, XXI (2): 73-76.

5. Wilson, T., Brokensha, H., Rowe, F., and Simpson, L. (2018). Insights from the evaluation of past local area population forecasts. Population Research and Policy Review 37(1): 137-155. doi:10.1007/s11113017-9450-4.

6. Rayer, S. (2008). Population forecast errors: A primer for planners. Journal of Planning Education and Research 27(4): 417-430. doi:10.1177/0739456X07313925.

7. Rayer, S. and Smith, S.K. (2014). Population projections by age for Florida and its counties: Assessing accuracy and the impact of adjustments. Population Research and Policy Review 33(5): 747-770. doi:10.1007/s11113-014-9325-x.

8. Statistics New Zealand (2008). How accurate are population projections? An evaluation of Statistics New Zealand population projections, 1991-2006. Wellington: Statistics New Zealand. http://archive.stats.govt.nz/browse_for_stats/population/ estimates_and_projections/how-accurate-arepopulation-projections.aspx. 
9. Tayman, J. (2011). Assessing uncertainty in small area forecasts: State of the practice and implementation strategy. Population Research and Policy Review 30(5): 781-800. doi:10.1007/s11113011-9210-9.

10. Yamauchi, M., Koike, S., and Kamata, K. (2017). How accurate are Japan's official subnational projections? Comparative analysis of projections in Japan, Englishspeaking countries and the EU. In: Swanson, D.A. (ed.). The frontiers of applied demography. Dordrecht: Springer: 305-328. doi:10.1007/978-3-319-43329-5_15.

11. Chi, G., Zhou, X. \& Voss, P.R. (2011). Small-area population forecasting in an urban setting: a spatial regression approach. J Pop Research 28:185-201. https://doi.org/10.1007/s12546-011-9053-6

12. Manojkumar Tiwari (2018), Waste water generation and quantity estimation, Week 2, Lecture 6, NPTEL, IIT Kharagpur

13. Hoque, M. A., Ahmed, F. and Sarker, M. M. (1995): An Estimation of future population of Bangladesh, Journal of Statistical Studies of Jahangir nagar University. 15:75-88.

14. Ara, S(2014). Impact of Temporal Population Distribution on Earthquake Loss Estimation: A Case Study on Sylhet, Bangladesh. Int J Disaster Risk Sci 5: 296-312 .https://doi.org/10.1007/s13753-014-0033-2 